\title{
AJUSTE DA LÂMINA DE IRRIGAÇÃO NO CULTIVO DE MILHO PARA SILAGEM NO VALE DO SUBMÉDIO SÃO FRANCISCO
}

\author{
Welson Lima Simões ${ }^{1}$, Miguel Júlio Machado Guimarães ${ }^{2}$, Hélio Tavares de Oliveira Neto ${ }^{3}$, Anderson \\ Ramos de Oliveira ${ }^{1}$ e Tadeu Vinhas Voltolini ${ }^{1}$
}

\begin{abstract}
${ }^{1}$ Pesquisador da Embrapa Semiárido, Rodovia BR-428, Km 152, Zona Rural, CP 23, CEP: 56302-970, Petrolina, PE,

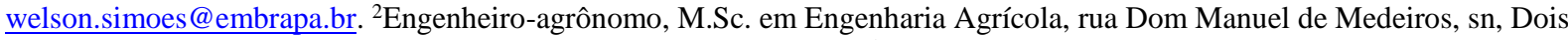
Irmãos, CEP: 52171-900, Recife - PE, mjmguimaraes@ hotmail.com. ${ }^{3}$ Engenheiro-agrônomo, UFCG, rua Aprígio Veloso 882, bairro universitário CEP: 58429-900, Campina Grande, PB, helio_tavaares@ hotmail.com ${ }^{1}$ Pesquisador da Embrapa Semiárido, Rodovia BR-428, Km 152, Zona Rural, CP 23, CEP: 56302-970, Petrolina, PE, anderson.oliveira@embrapa.br. ${ }^{1}$ Pesquisador da Embrapa Semiárido, Rodovia BR-428, Km 152, Zona Rural, CP 23, CEP: 56302-970, Petrolina, PE, tadeu.voltolini@embrapa.br.
\end{abstract}

RESUMO - O milho se destaca entre as demais culturas pela sua qualidade nutricional e produtividade para o uso em silagem animal. O uso da água de forma racional atua positivamente no que diz respeito ao acúmulo de fitomassa e eficiência de produção. Neste contexto, o presente trabalho teve o objetivo de avaliar o crescimento e a produtividade de biomassa da variedade do milho BRS Gorutuba para silagem, sob diferentes lâminas de irrigação na região do Submédio do Vale do São Francisco. Adotou-se o delineamento experimental em blocos ao acaso, com lâminas de irrigação de 30, 6090 e $120 \%$ da evapotranspiração da cultura (ETc). Foram avaliadas características biométricas de crescimento e desenvolvimento e de produtividade. As variáveis altura de plantas e número de folhas por planta tiveram acréscimos em função do aumento das lâminas de irrigação. O maior diâmetro do caule foi alcançado com lâmina próxima a $90 \%$ de reposição da ETc. Os níveis de água disponível no solo influenciaram significativamente o desenvolvimento do milho BRS Gorutuba para região do Vale do Submédio São Francisco. A variedade BRS Gorutuba apresenta-se sensível à restrição hídrica para fins de produção de silagem, sendo os maiores rendimentos de biomassa alcançados com o uso de $120 \%$ da ETc, para o coeficiente de cultura utilizado.

PALAVRAS-CHAVE: Silagem. BRS Gorutuba. Eficiência no uso da água. Semiárido.

ABSTRACT- Corn stands out among other crops for its nutritional quality and productivity for use in animal silage. The use of water in a rational way acts positively with respect to the accumulation of phytomass and production efficiency. In this context, the present work had the objective of evaluating the biomass productivity of the BRS Gorutuba corn variety for silage, under different irrigation slides in the Submedia region of the São Francisco Valley. The experimental design was a randomized block design with irrigation slides of 30, 60, 90 and $120 \%$ of crop evapotranspiration (ETc). Biometric growth and development parameters and productivity parameters were evaluated. The variables plant height and number of leaves per plant had increases due to the increase of the irrigation slides. The largest diameter of the stem was reached with a blade close to $90 \%$ of ETc replacement. The levels of available water in the soil significantly influenced the development of BRS Gorutuba maize to the region of the SubSão Francisco Valley. The BRS Gorutuba variety is sensitive to water restriction for silage production, with the highest yields of biomass being achieved with the use of $120 \% \mathrm{ETc}$, for the crop coefficient used.

KEY WORDS: Silage. BRS Gorutuba. Efficiency in water use. Semi-arid.

\section{INTRODUÇÃO}

A disponibilidade de recursos alimentares para suprir as necessidades de um rebanho em período de escassez de alimentos é um aspecto de grande relevância e que não pode ser negligenciado numa propriedade agrícola, quer seja voltada para a produção animal ou para a simples manutenção dos rebanhos de subsistência. Na região Semiárida, caracterizada por 
períodos de estiagem prolongada, a disponibilidade de alimentos é um ponto crítico dentro do sistema agrícola. Nestas condições, a produção excedente de biomassa verde durante o período chuvoso deve ser armazenada para fins de utilização no período de escassez. Dentre as opções de armazenamento e conservação, a técnica da silagem da biomassa é uma das mais recomendadas, uma vez que esta é bem aceita pelos animais, mantém o valor nutricional por período prolongado e, considerando-se o aspecto de infraestrutura, pode ser armazenada em espaços pequenos na forma de fardos herméticos, trincheiras ou estruturas verticais próprias para armazenamento, chamadas silos (DOONAN et al., 2004; NEGRÃO; DANTAS, 2010).

A silagem consiste na conservação de forrageiras ou leguminosas (biomassa vegetal) por meio da fermentação anaeróbica, uma vez que esta interrompe o processo de degradação da matéria orgânica (DOONAN et al., 2004). Dentre as forrageiras, o milho se destaca devido ao seu elevado valor nutricional, boa digestibilidade e alto rendimento de massa verde por hectare, tornando-se atrativo para os produtores. Além disso, o milho é uma cultura que se apresenta favorável ao processo de ensilagem, devido à manutenção de níveis adequados de pH, o que é desejável numa condição anaeróbica (POSSENTI et al., 2005). Resende et al. (2017) acrescentam outros aspectos positivos da ensilagem do milho que são a disponibilidade de híbridos adaptados aos diferentes ambientes, a facilidade de fermentação natural e a maior densidade energética devido à presença de grãos.

Diversos trabalhos têm mostrado a viabilidade de uso do milho em processos de ensilagem. Ribeiro Junior et al. (2011) constataram que a silagem do milho pode ser utilizada com sucesso no balanceamento de dietas de vacas leiteiras, com vistas a alta produção, uma vez que o milho sendo utilizado como volumoso proporciona dietas com elevada qualidade nutricional. Oliveira et al. (2017) acrescentam que de forma geral, a silagem de milho produzida na maioria das propriedades tem satisfatório valor nutritivo, com destaque para a concentração de amido.

Na seleção de cultivares ou híbridos para serem utilizados no processo de silagem devem ser considerados o teor de matéria seca e a composição bromatológica, sabendo-se que materiais diferentes podem ser destinados à produção de grãos, à produção de milho verde ou à produção de milho para silagem. Contudo, Ribeiro Junior et al. (2011) alertam que além do teor de matéria seca e da composição do grão que reflete a qualidade nutricional, o híbrido selecionado deve ter boa aceitação pelos animais. No mercado existem diversos híbridos, os quais estão sendo objeto de estudos para recomendações de materiais com maior potencial de produção de silagem. Vieira et al. (2015) ao estudarem híbridos de milho para a produção de silagem, selecionaram os híbridos 30F35H e AG8088-PRO, por apresentarem alta produtividade, qualidade, ciclo precoce e melhores características agronômicas e qualitativas adequadas para produção de silagem. Em outro estudo, Neves et al. (2015) concluíram que os materiais BRS 3035, BRS 2022 e BRS CAIMBÉ obtiveram elevadas produções de matéria seca $\left(9,68,9,66\right.$ e $8,62 \mathrm{Mg} \mathrm{ha}^{-1}$, respectivamente) e que poderiam ser recomendados para silagem. Couto et al. (2017), avaliando o desempenho de 37 cultivares de milho por meio de características biométricas e produtivas, constataram que as cultivares CD 324PRO2, AL AVARE e CD 3715PRO podem ser destinadas à produção de silagem.

Em regiões com limitações hídricas, além da seleção do híbrido ou cultivar de milho mais produtiva e de boa qualidade de biomassa, a identificação de materiais que apresentem elevada eficiência no uso da água são desejáveis, uma vez que podem aumentar o potencial de sucesso da atividade devido à vantagem de tolerarem melhor o déficit hídrico ou mesmo alcançarem elevadas produtividades utilizando-se menores lâminas de água, quando cultivadas em sistemas irrigados.

O milho é uma gramínea altamente suscetível ao estresse hídrico e pode ter seu rendimento altamente comprometido se houver estiagem durante os períodos críticos de desenvolvimento como o florescimento e a maturação fisiológica (CARVALHO et al., 2013). 
A demanda hídrica da cultura é variável de acordo com a cultivar e também com as condições climáticas do local de cultivo. De acordo com Albuquerque (2010) esta demanda pode variar de 380 a $550 \mathrm{~mm}$ durante todo o ciclo de desenvolvimento. Segundo Chun et al. (2011), a redução da disponibilidade hídrica ocasiona estresse às plantas de milho e reduz seu crescimento, mesmo sob condições de atmosfera modificada com aumento de $\mathrm{CO}_{2}$. Bernardo, Soares e Mantovani (2006) também relatam que a quantidade de água necessária para determinada cultura é um dado básico que deve ser conhecido para o manejo adequado de qualquer projeto de irrigação. Assim, o conhecimento do comportamento de determinada cultivar diante do estresse hídrico pode resultar em economia de água, caso a cultivar se manifeste tolerante ao estresse por meio de sua eficiência no uso da água. Aspecto importante nesta forma de manejo é que irrigações excessivas acarretam perda de água e nutrientes, pela percolação abaixo da zona das raízes, além de favorecer a proliferação de microrganismos patogênicos (COSTA, 2004).

Diante da contínua diminuição da oferta de recursos hídricos, principalmente em regiões semiáridas, é imperativo que os mesmos sejam utilizados de forma racional para garantir a sustentabilidade e a maximização da produção (BENJAMIN et al., 2014).

Neste contexto, o presente trabalho teve o objetivo de avaliar o crescimento e a produtividade de biomassa da variedade do milho BRS Gorutuba para silagem, sob diferentes lâminas de irrigação na região do Submédio do Vale do São Francisco.

\section{MATERIAL E MÉTODOS}

$\mathrm{O}$ estudo foi conduzido em Campo Experimental pertencente à Embrapa Produtos e Mercados, em Petrolina, PE, latitude 9 $8^{\prime} 8,9^{\prime \prime}$ e longitude $40^{\circ} 18^{\prime} 33,6^{\prime \prime}$, em altitude de $373 \mathrm{~m}$. O clima da região é classificado como semiárido, do tipo BSwh' quente e seco. Durante o período do estudo a umidade relativa do ar média foi de $47,3 \%$ e a temperatura média de $27,5^{\circ} \mathrm{C}$, com uma evapotranspiração máxima de 8,03 e média de $6,1 \mathrm{~mm}$ dia $^{-1}$. Não houve eventos de precipitação efetiva acima de $5 \mathrm{~mm} \mathrm{dia}^{-1}$.

Foi adotado o delineamento experimental em blocos ao acaso, com quatro repetições. A variedade de milho selecionada foi a BRS Gorutuba, muito utilizada para a produção de biomassa para alimentação animal no Semiárido brasileiro. As plantas foram submetidas a lâminas de irrigação de 30; 60; 90; e 120\% da evapotranspiração da cultura (ETc). Cada unidade experimental foi formada por cinco fileiras de cinco metros de comprimento, sendo fixadas 10 plantas por metro linear com 0,5 m entre linhas (200.000 plantas ha $\left.{ }^{-1}\right)$, perfazendo uma área de $12,5 \mathrm{~m}^{2}$, considerando-se úteis as plantas das fileiras centrais, eliminando-se os metros iniciais e finais de cada fileira. O plantio foi realizado em 24 de agosto de 2015.

O solo da área experimental foi classificado como Latossolo Vermelho Amarelo textura média, apresentando relevo plano. A área foi preparada conforme necessidade da cultura, realizando-se aração e gradagem. Foram coletadas amostras de solos, na camada de 0 a $20 \mathrm{~cm}$, para caracterização química no Laboratório de Água e Solo da Embrapa Semiárido. A adubação de fundação foi realizada com base nesta análise (Tabela 1), sendo aplicados $30 \mathrm{~kg} \mathrm{ha}^{-1} \mathrm{de}$ nitrogênio $(\mathrm{N}), 60 \mathrm{~kg} \mathrm{ha}^{-1}$ de fósforo $\left(\mathrm{P}_{2} \mathrm{O}_{5}\right)$ e $20 \mathrm{~kg} \mathrm{ha}^{-1}$ de potássio $\left(\mathrm{K}_{2} \mathrm{O}\right)$. Aos 30 dias após o plantio foi realizada uma adubação nitrogenada de cobertura com $30 \mathrm{~kg} \mathrm{ha}^{-1}$. 
Tabela 1. Características químicas do solo estudado.

\begin{tabular}{|c|c|c|c|c|c|c|c|c|c|c|c|c|}
\hline $\mathrm{pH}$ & $\mathrm{P}$ & K & $\mathrm{Ca}^{2+}$ & $\mathrm{Mg}^{2+}$ & $\mathrm{Al}^{3+}$ & $\mathrm{H}+\mathrm{Al}^{3+}$ & $\mathrm{Na}^{+}$ & S & CTC & V & $\mathrm{CE}$ & M.O \\
\hline $\mathrm{H}_{2} \mathrm{O}$ & $\mathrm{mg} \mathrm{dm}^{-3}$ & & - & י-י-י-ים & - & $\mathrm{mol}_{\mathrm{c}} \mathrm{dm}$ & - & ------ & 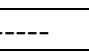 & $\%$ & $\mathrm{dS} \mathrm{m^{-1 }}$ & $\mathrm{g} \mathrm{kg}^{-1}$ \\
\hline 5,00 & 2,91 & 0,32 & 1,00 & 0,50 & 0,00 & 5,00 & 0,05 & 1,87 & 6,87 & 27,22 & 0,79 & 2,90 \\
\hline
\end{tabular}

As lâminas de água aplicadas por tratamento foram calculadas de acordo com a evapotranspiração da cultura (ETo* Kc* $\mathrm{Kl})$, a precipitação ocorrida e a eficiência de aplicação de água do sistema de irrigação, conforme a equação seguinte:

$$
\mathrm{Li}=\frac{(\mathrm{ETo} * \mathrm{Kc})-\mathrm{P}}{\mathrm{Ef}}
$$

em que:

Li - Lâmina de irrigação (mm);

ETo - Evapotranspiração estimada no período (mm);

Kc - Coeficiente de cultivo da cultura (Allen et al., 1998);

$\mathrm{Kl}$ - Coeficiente de localização;

$\mathrm{P}$ - Precipitação medida no período (mm);

Ef - Eficiência do sistema de irrigação, 0,9.

Os valores de ETo foram obtidos de uma estação meteorológica instalada próxima ao local do experimento e os coeficientes de localização $(\mathrm{Kl})$ pela média de quatro medidas no campo, conforme citados por Pizarro (1996), que dependem do valor da fração de área sombreada pelo cultivo durante o ciclo. A precipitação ocorrida neste período foi de apenas 4 mm, a qual não foi considerada no cálculo das lâminas de irrigação.

O sistema de irrigação adotado foi o de tubo de gotejamento, com espaçamento de 0,30 m e vazão de $2 \mathrm{~L} \mathrm{~h}^{-1}$, sendo uma linha de gotejo por fileira de planta, e as irrigações com intervalo de um dia.

A colheita foi realizada no mês de novembro, quando as plantas estavam no início da emissão das espigas. As plantas da parcela útil foram cortadas a uma altura de $10 \mathrm{~cm}$ do solo, e foram avaliados os seguintes parâmetros: altura da planta, diâmetro do caule, número de folhas, comprimento e largura da folha +3 e biomassa fresca. Posteriormente o material foi colocado em estufa para secar a $60^{\circ} \mathrm{C}$ até obter um peso constante para determinação da biomassa seca.

Os dados obtidos foram submetidos à análise de variância (ANOVA) utilizando o programa Sisvar 5.0 (FERREIRA, 2014). Para comparação entre as lâminas de irrigação, foram avaliados modelos de regressão de primeiro e segundo graus quando significativos ao nível de $1 \%$ ou $5 \%$ de probabilidade.

\section{RESULTADOS E DISCUSSÃO}

Na Tabela 2 é apresentado o resumo da análise de variância para as variáveis estudadas. Pode-se observar que a aplicação de lâminas de irrigação influenciou significativamente a altura, o diâmetro e o número de folhas das plantas de milho, bem como a produtividade de biomassas fresca e seca. Observa-se também que as lâminas de água não influenciaram nas características biométricas das folhas (largura e comprimento). 
ISSN 2525-9075 on-line

Tabela 2. Resumo da análise estatística de variáveis biométricas e produtivas de milho para alimentação animal submetido a lâminas de irrigação no Submédio do Vale do são Francisco.

\begin{tabular}{|c|c|c|c|c|c|c|c|}
\hline \multirow{2}{*}{ Fonte de variação } & \multirow{2}{*}{$\begin{array}{l}\text { Altura } \\
(\mathrm{cm})\end{array}$} & \multirow{2}{*}{$\begin{array}{l}\text { Diâmetro } \\
(\mathrm{mm})\end{array}$} & \multirow{2}{*}{ N. ${ }^{\circ}$ folha } & \multicolumn{2}{|c|}{ Folha $+3(\mathrm{~cm})$} & \multicolumn{2}{|c|}{ Produtividade $\left(\mathrm{t} \mathrm{ha}^{-1}\right)$} \\
\hline & & & & Largura & Comprimento & B. Fresca & B. Seca \\
\hline Bloco & $1,115^{\mathrm{ns}}$ & $0,692^{\mathrm{ns}}$ & $0,429^{\mathrm{ns}}$ & $0,219^{\mathrm{ns}}$ & $3,736^{\mathrm{ns}}$ & $0,387^{\mathrm{ns}}$ & $0,964^{\mathrm{ns}}$ \\
\hline Lâminas de irrigação & $30,608^{* *}$ & $21,045^{* *}$ & $17,143^{* *}$ & $2,009^{\mathrm{ns}}$ & $3,488^{\mathrm{ns}}$ & $27,277^{* *}$ & $57,89^{* *}$ \\
\hline Coeficiente de variação (\%) & 8,3 & 7,6 & 5,88 & 7,0 & 6,0 & 13,2 & 9,9 \\
\hline Média geral & 120,6 & 16,0 & 8,6 & 9,0 & 77,7 & 29,3 & 9,7 \\
\hline
\end{tabular}

Depreende-se das Figuras 1 e 2 que na medida em que se aumentou a lâmina de água, a altura e o número de folhas cresceram de forma linear. Tais parâmetros estão diretamente relacionados à disponibilidade hídrica, pois sendo o milho uma cultura exigente em água, a reposição hídrica promove a expansão celular e, consequentemente, o crescimento em altura e o surgimento de folhas ao longo do caule. O processo fotossintético exercido pelas folhas é influenciado pela disponibilidade hídrica, podendo ocorrer fechamento de estômatos em condições de escassez, o que resulta em redução na taxa de crescimento e de emissão de folhas. De acordo com Costa et al. (2009), ainda que a taxa de aparecimento de folhas seja uma característica determinada geneticamente, a mesma é influenciada por variáveis ambientais como temperatura, disponibilidade hídrica e de nutrientes. Em espécies do tipo C4 (gramíneas) é comum que o crescimento em altura se perpetue até que ocorra uma restrição hídrica ou que a cultura entre na fase fisiológica reprodutiva, iniciada pelo florescimento (ROCHA et al., 2007; DIOLA; SANTOS, 2010).

Os resultados se assemelham aos observados por Almeida et al. (2015) que avaliaram as características de crescimento e de produtividade do milho sob diferentes lâminas de irrigação e adubação nitrogenada. Os pesquisadores constataram que os dados da variável altura se ajustaram a curva quadrática, onde as lâminas de 100 e $125 \%$, em relação ao teor de água do solo, foram as que alcançaram os melhores resultados, com 2,20 m aproximadamente. BonfimSilva et al. (2011), trabalhando com gramíneas (milho, sorgo e milheto) submetidas a estresse hídrico, verificaram aumento significativo nas mesmas variáveis analisadas, com disponibilidade hídrica de $60 \%$ da capacidade de campo. Já para a disponibilidade hídrica de $30 \%$, o milho apresentou menor desenvolvimento, que permite inferir que esta cultura apresenta baixa tolerância à seca em seu desenvolvimento inicial.

Figura 1. Altura de plantas de milho submetidas a diferentes lâminas de irrigação no Submédio do Vale do São Francisco.

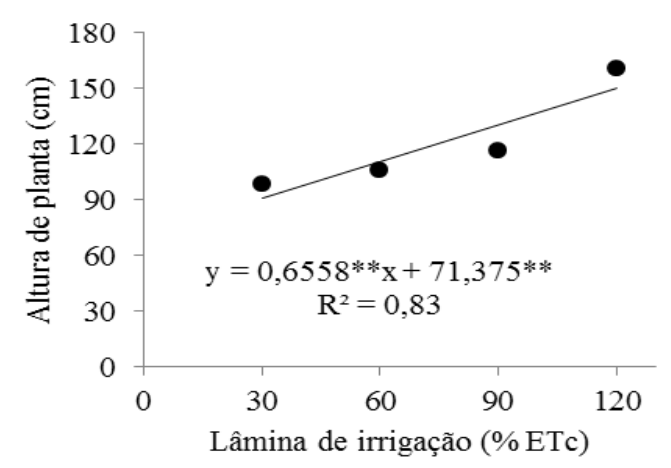

**, * coeficiente de regressão significativo a 0,01 e 0,05 de probabilidade, respectivamente
Figura 2. Número de folhas de plantas de milho submetidas a diferentes lâminas de irrigação no Submédio do Vale do São Francisco.

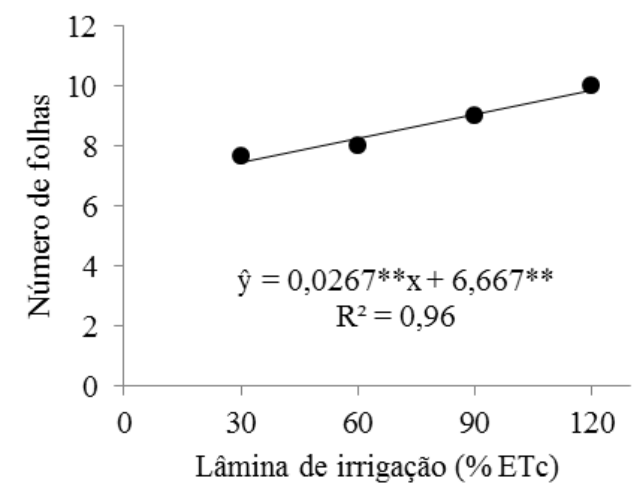

**, * coeficiente de regressão significativo a 0,01 e 0,05 de probabilidade, respectivamente 
O diâmetro do colmo (Figura 3) apresentou efeito quadrático, com diâmetro máximo quando se aplicou $90 \%$ da ETc da cultura. Isso mostra o quanto a cultura é sensível, seja por falta ou excesso de água. O desenvolvimento do caule de plantas de milho se acentua, notadamente, após a emissão da oitava folha, sendo este responsável por dar suporte as folhas e inflorescências e, posteriormente, garantir que o sustento das espigas, além disso, constituise em estrutura de armazenamento de fotoassimilados, os quais poderão migrar para a parte reprodutiva durante o processo de maturação (FANCELLI e DOURADO NETO, 2000). De acordo com Santos Neto (2012), o caule tem papel relevante, uma vez que quanto maior for o diâmetro, maior será a capacidade de a planta armazenar sólidos solúveis, aumentando o rendimento de espiguetas.

Os resultados se assemelham aos encontrados por Santos et al. (2016) que ao estudarem o desenvolvimento e a produção do milho BRS Gorutuba quando cultivados em diferentes níveis de disponibilidade de água e adubo orgânico, constataram que o diâmetro do caule também descreve uma curva de crescimento quadrática atingindo seu máximo sem que ocorra a total reposição da ETc.

Figura 3. Diâmetro do caule de plantas de milho submetidas a diferentes lâminas de irrigação no Submédio do Vale do São Francisco.

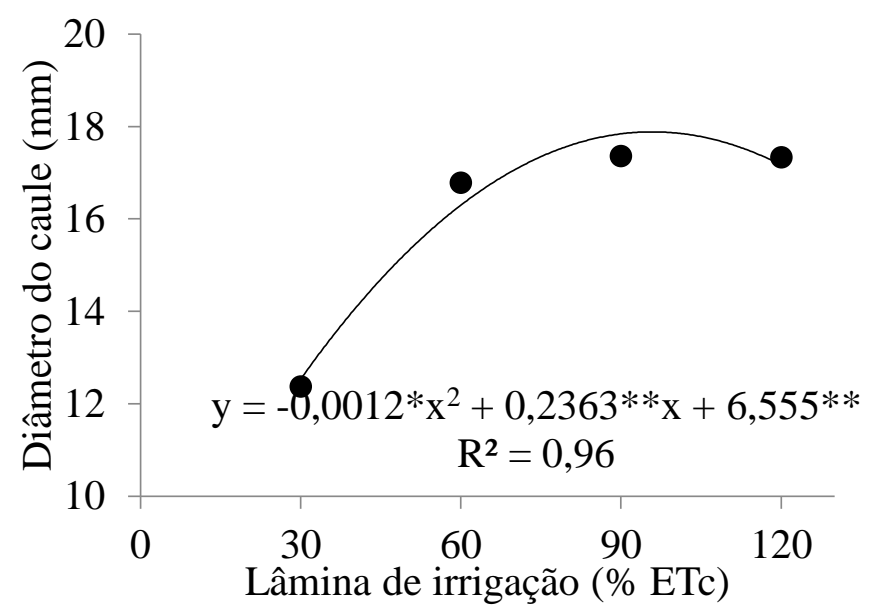

**, * coeficiente de regressão significativo a 0,01 e 0,05 de probabilidade, respectivamente

A produtividade das biomassas fresca e seca (Figuras 4 e 5) apresentou diferença significativa entre os tratamentos, demonstrando uma relação linear com as lâminas utilizadas. Isso mostra o quanto a cultura é exigente em água e como as lâminas influenciaram de forma diferenciada os componentes de crescimento e produção do milho. Silva et al. (2012) em estudo sobre o desempenho agronômico de genótipos de milho sob estresse hídrico, também verificaram que a produtividade é reduzida com restrição hídrica, ocorrendo senescência prematura de folhas, redução de fotossíntese e decréscimo na produção de fitomassa.

Para o milho BRS Gorutuba, a produtividade da biomassa fresca e seca aumentou com a disponibilidade de água, atingindo valores máximos quando houve reposição de $120 \%$ da ETc. Os resultados corroboram o trabalho de Souza et al. (2014), que tiveram como base para irrigação a evapotranspiração de referência (Eto) e verificaram que maior acúmulo de biomassa seca da parte aérea foi obtido com lâminas próximas a 100\%. Viana et al. (2004) também observaram resultados semelhantes, em que se verificou redução de $10 \%$ na produção de biomassa na cultura do milho sob estresse hídrico. Brito et al. (2013), trabalhando com milho 
doce sob estresse hídrico, observaram que as variáveis diâmetro do colmo e massa seca do colmo são muito sensíveis ao estresse hídrico e destacaram que lâminas inferiores a $80 \%$ da ETc influenciam negativamente no crescimento das plantas de milho.

Figura 4. Produtividade de Biomassa Fresca $(\mathrm{BF})$ de plantas de milho submetidas a diferentes lâminas de irrigação no Submédio do Vale do São Francisco.

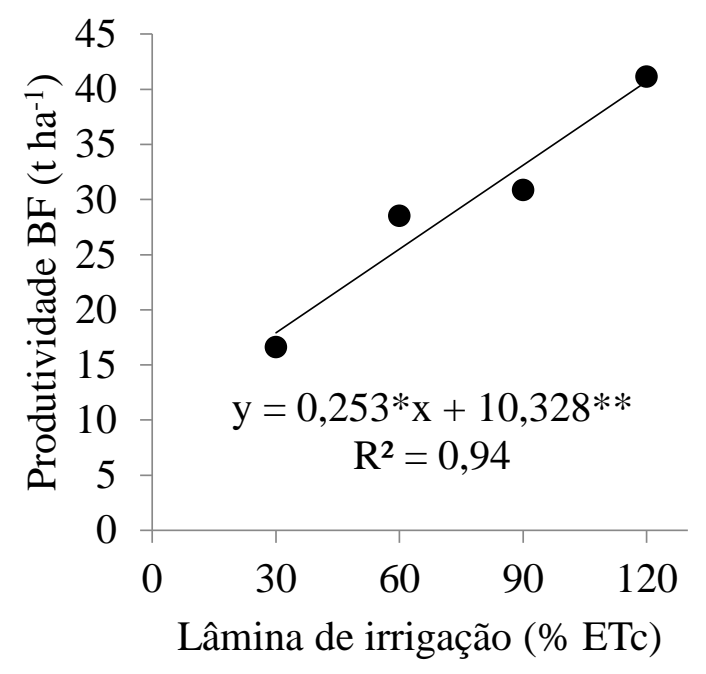

**, * coeficiente de regressão significativo a 0,01 e 0,05 de probabilidade, respectivamente
Figura 5. Produtividade de Biomassa Seca (BS) de plantas de milho submetidas a diferentes lâminas de irrigação no Submédio do Vale do São Francisco.

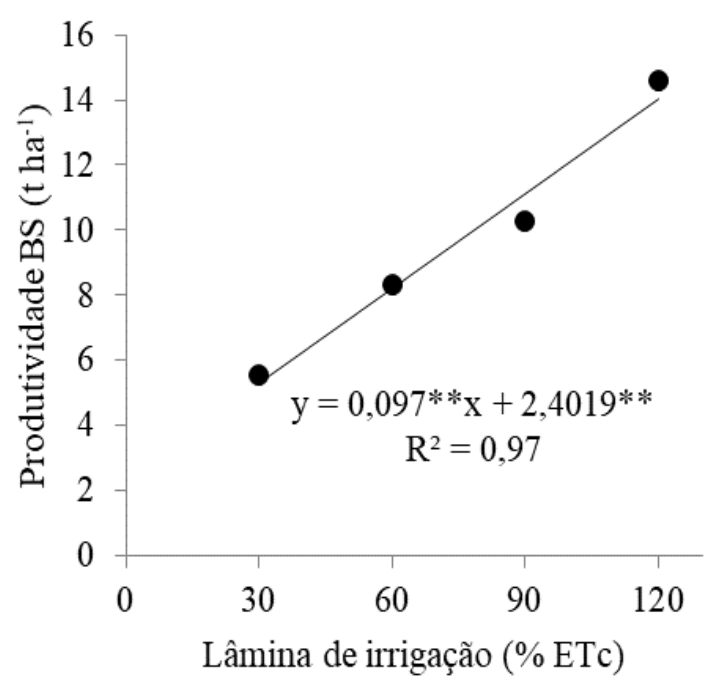

**, * coeficiente de regressão significativo a 0,01 e 0,05 de probabilidade, respectivamente

Amaral et al. (2016) avaliando o desempenho de cultivares de milho sob estresse hídrico verificaram que a biomassa seca da parte aérea é influenciada pelas lâminas, porém a redução de até $30 \%$ na lâmina de água aplicada não causou redução significativa no rendimento dos genótipos. Por outro lado, reduções nas lâminas de irrigação maiores que 50\% reduziram a produtividade de biomassa seca de todos os materiais analisados.

Os resultados encontrados também corroboram Costa, Pinho e Parry et al. (2008) que observaram que a biomassa da parte aérea do milho é influenciada negativamente por níveis menores que $50 \%$ de disponibilidade hídrica, tanto no período vegetativo, quanto no reprodutivo. Demonstram também que o Kc utilizado neste trabalho, indicado para milho por Allen et al. (1998), é inferior ao exigido pela variedade BRS Gorutuba para seu cultivo na região do Vale do Submédio São Francisco.

\section{CONCLUSÕES}

Os níveis de água disponível no solo influenciaram significativamente o desenvolvimento do milho BRS Gorutuba para região do Vale do Submédio São Francisco;

A variedade BRS Gorutuba apresenta-se sensível à restrição hídrica para fins de produção de silagem, sendo os maiores rendimentos de biomassa alcançados com o uso de $120 \%$ da ETc, para o coeficiente de cultura utilizado.

\section{REFERÊNCIAS}

ALBUQUERQUE, P. E. P. Manejo de irrigação na cultura do milho. Embrapa Milho e Sorgo. Sistema de Produção, 1 ISSN 1679-012X Versão Eletrônica - 6ª edição Set./2010. 


\section{DN NTELLETTO}

ISSN 2525-9075 on-line

ALLEN, R. G.; PEREIRA, L. S.; RAES, D.; SMITH, M. Crop evapotranspiration:

Guidelines for computing crop water requirements. Rome: FAO, 1998. 300 p. (FAO Irrigation and Drainage Paper, 56).

ALMEIDA, K. F.; CASTRO JÚNIOR, W. L.; SANTOS, E. B.; SILVA, Y. N. M.; SOUSA, C. L. Avaliação da produtividade do milho (Zea mays L.) sob diferentes lâminas de irrigação e doses de adubação nitrogenada na região dos cocais maranhense. In: Congresso Nacional de Irrigação e Drenagem, 25., 2015, São Cristóvão. Anais... Brasília: ABID, 2016. p. 486 -491.

AMARAL, T. A.; ANDRADE, C. L. T.; SOUZA, V. F.; PAIXÃO, J. S. Resposta de cultivares de milho ao estresse hídrico. Sete Lagoas: Embrapa Milho e Sorgo, 2016. 25 p. (Embrapa Milho e Sorgo. Documentos, 207).

BENJAMIN, J.G.; NIELSEN, D.C.; VIGIL, M.F.; MIKHA, M.M.; CALDERON, F. Water deficit stress on corn (Zea mays L.) root: shoot ratio. Journal of Soil Science, v.4, p.151-160, 2014.

BERNARDO, S; SOARES, A. A.; MANTOVANI, E. C. Manual de irrigação. Viçosa: UFV, 2006. $625 \mathrm{p}$.

BRITO, M. E. B.; ARAÚJO FILHO, G. D.; WANDERLEY, J. A. C.; MELO, A. S.; COSTA, F. B.; FERREIRA, M. G. P. Crescimento, fisiologia e produção do milho doce sob estresse hídrico. Bioscience Journal, Uberlândia, v. 29, n. 5, p. 1244-1254, 2013.

CARVALHO, V. R.; KORCELSKI, C.; PELISSARI, G.; HANUS, A. D.; ROSA, G. M. Demanda hídrica das culturas de interesse agronômico. Enciclopédia Biosfera, Centro Científico Conhecer, Goiânia, v. 9, n. 17, p. 969-985, 2013.

CHUN, J. A.; WANG, Q.; TIMLIN, D.; FLEISHER, D.; REDDY, V. R. Effect of elevated carbon dioxide and water stress on gas exchange and water use efficiency in corn.

Agricultural and Forest Meteorology, New Haven, v. 151, n. 3, p. 378-384, 2011.

COSTA, J. R.; PINHO, J. L. N.; PARRY, M. M. Produção de matéria seca de cultivares de milho sob diferentes níveis de estresse hídrico. Revista Brasileira de Engenharia Agrícola e Ambiental, Campina Grande, v. 12, n. 5, p. 443-450, 2008.

COSTA, N. L.; GIANLUPPI, V.; BENDAHAN, A. B.; BRAGA, R. M.; MATTOS, P. S R. Fisiologia e manejo de gramíneas forrageiras tropicais. Boa Vista, RR: Embrapa Roraima, 2009. (Embrapa Roraima. Documentos, 17).

COSTA, S. V. Desenvolvimento e calibração de um mini-tanque evaporimétrico. 2004. 80f. Dissertação (Mestrado em Engenharia Agrícola) - Universidade Federal de Santa Maria, Santa Maria, 2004.

COUTO, C. A.; SILVA, E. M.; SILVA, A. G.; OLIVEIRA, M. T. P.; VASCONCELOS, J. C.; SILVA, A. R.; SOBREIRA, E. A.; MOURA, J. B. Desempenho de cultivares de milho destinados para produção de milho verde e silagem. Fronteiras: Journal of Social, Technological and Environmental Science, v.6, n.1, p. 232-251, 2017. 


\section{DN NTELLETTO}

ISSN 2525-9075 on-line

DIOLA, V.; SANTOS, F. Fisiologia. In: SANTOS, F.; BORÉM, A.; CALDAS, C. Cana-deaçúcar: bioenergia, açúcar e álcool: tecnologias e perspectivas. Viçosa: Editora UFV. p. 25-49, 2010.

DOONAN, B. M.; KAISER, A. G.; STANLEY, D. F.; BLACKWOOD, I. F.; PILTZ, J. W.; WHITE, A.K. Silage in the farming system. In: KAISER, A. G.; PILTZ, J. W.; BURNS, H. M.; GRIFFITHS, N. W. (Ed.) Successful Silage. Orange: KAISER, A. G.; PILTZ, J. W.; BURNS, H. M.; GRIFFITHS, N. W., 2004. p.1-24.

FANCELlI, A. L.; DOURADO NETO, D. Produção de milho. Guaíba: Agropecuária, 2000. 360 p.

FERREIRA, D. F. Sisvar: a guide for its bootstrap procedures in multiple comparisons. Ciência e Agrotecnologia, Lavras, v. 38, n. 2, p. 109-112, 2014.

NEGRÃO, F. M.; DANTAS, C.C.O. Produção de silagem de milho e capim-elefante. Pubvet, Londrina, v. 4, n. 27, 2010.

NEVES, A. L. A.; SANTOS, R. D.; PEREIRA, L. G. R.; TABOSA, J. N.; ALBUQUERQUE, I. R. R.; NEVES, A. L. A.; OLIVEIRA, G. F.; VERNEQUE, R. S. Agronomic characteristics of corn cultivars for silage production. Semina: Ciências Agrárias, v. 36, n. 3, p. 1799-1806, 2015.

OLIVEIRA, I. L.; LIMA, L. M.; CASAGRANDE, D. R.; LARA, M. A. S.; BERNARDES, T. F. Nutritive value of corn silage from intensive dairy farms in Brazil. Revista Brasileira de Zootecnia, v.46, n.6, p.494-50, 2017.

POSSENTI, R. A.; FERRARI JUNIOR, E.; BUENO, M. S.; BIANCHINI, D.; LEINZ, F. F.; RODRIGUES, C. F. Parâmetros bromatológicos e fermentativos das silagens de milho e girassol. Ciência Rural, v.35, n.5, p.1185-1189, 2005.

RESENDE, H.; OLIVEIRA, J. S.; MIRANDA, J. E. C.; LEITE, J. L. B. Tecnologia e custo da silagem de milho. Juiz de Fora: Embrapa Gado de Leite, 2017. 11 p. (Embrapa Gado de Leite. Circular Técnica, 114).

RIBEIRO JUNIOR, C. S.; SALCEDO, Y. T. G.; AZEVEDO, R. A.; DELEVATTI, L. M.; MACHADO, M. Uso de silagem de milho no balanceamento de dietas para vacas leiteiras. Enciclopédia Biosfera, Centro Científico Conhecer, Goiânia, v. 7, n. 13, p. 1010-1018, 2011.

ROCHA, M. G.; QUADROS, F. L. F.; GLIENKE, C. L.; CONFORTIN, A. C. C.; COSTA, V. G.; ROSSI, G. E. Avaliação de espécies forrageiras de inverno na Depressão Central do Rio Grande do Sul. Revista Brasileira de Zootecnia, v. 36, n. 6, p.1990-1999, 2007, (supl.).

SANTOS NETO, I. J. Cultivares de milho e lâminas de irrigação para produção de minimilho em Vitória da Conquista-BA, 2012. 66f. Dissertação (Mestrado em Agronomia) - Universidade Estadual do Sudoeste da Bahia, Vitória da Conquista, 2012.

SANTOS, M. L. S.; SILVA, M. R. B.; SANTOS, J. M. R.; MELO, R. F.; GUIMARÃES, M. J. M. Desenvolvimento e produção do milho BRS Gorutuba submetido a diferentes níveis de 


\section{W WNTELLETO}

ISSN 2525-9075 on-line

disponibilidade de água no solo e adubo orgânico. In: JORNADA DE INICIAÇÃO CIENTÍFICA DA EMBRAPA SEMIÁRIDO, 11, 2016, Petrolina. Anais... Petrolina:

Embrapa Semiárido, 2016. p. 185-190. 1 CD-ROM. (Embrapa Semiárido. Documentos, 271).

SILVA, M. R.; MARTIN, T. N.; ORTIZ, S.; BERTONCELLI, P.; VONZ, D. Desempenho agronômico de genótipos de milho sob condições de restrição hídrica. Revista de Ciências Agrárias, v.35, n.1, p.202-212, 2012.

SOUZA, L. S. B.; MOURA, M. S. B.; SEDIYAMA, G. C.; SILVA, T. G. F. Crescimento e produtividade do milho e feijão-caupi em diferentes sistemas e disponibilidade hídrica no Semiárido. Revista Brasileira de Geografia Física, Recife, v.7, n.3, p. 524-539, 2014.

VIEIRA, A. F.; NUNES, R. L. C.; TORRES, R. A.; DIAS, N. S.; OLIVEIRA, A. B. Avaliação agronômica de híbridos de milho para silagem em Baraúna, região Semiárida Nordestina. Revista Brasileira de Milho e Sorgo, Sete Lagoas, v. 14, n. 2, p. 283-290, 2015.

BONFIM-SILVA, E. M.; SILVA, T. J. A.; CABRAL, C. E. A.; KROTH, B. E.; REZENDE, D. Desenvolvimento inicial de gramíneas submetidas ao estresse hídrico. Revista Caatinga, Mossoró, v. 24, n. 2, p. 180-186, 2011.

Recebido para publicação: 03 de novembro de 2017

Aprovado: 08 de dezembro de 2017. 